\title{
Comparative proteomic analysis between nitrogen supplemented and starved conditions in Magnaporthe oryzae
}

\author{
Yeonyee Oh', Suzanne L. Robertson², Jennifer Parker², David C. Muddiman² and Ralph A. Dean ${ }^{1 *}$
}

\begin{abstract}
Background: Fungi are constantly exposed to nitrogen limiting environments, and thus the efficient regulation of nitrogen metabolism is essential for their survival, growth, development and pathogenicity. To understand how the rice blast pathogen Magnaporthe oryzae copes with limited nitrogen availability, a global proteome analysis under nitrogen supplemented and nitrogen starved conditions was completed.

Methods: M. oryzae strain 70-15 was cultivated in liquid minimal media and transferred to media with nitrate or without a nitrogen source. Proteins were isolated and subjected to unfractionated gel-free based liquid chromatography-tandem mass spectrometry (LC-MS/MS). The subcellular localization and function of the identified proteins were predicted using bioinformatics tools.

Results: A total of 5498 M. oryzae proteins were identified. Comparative analysis of protein expression showed 363 proteins and 266 proteins significantly induced or uniquely expressed under nitrogen starved or nitrogen supplemented conditions, respectively. A functional analysis of differentially expressed proteins revealed that during nitrogen starvation nitrogen catabolite repression, melanin biosynthesis, protein degradation and protein translation pathways underwent extensive alterations. In addition, nitrogen starvation induced accumulation of various extracellular proteins including small extracellular proteins consistent with observations of a link between nitrogen starvation and the development of pathogenicity in M. oryzae.
\end{abstract}

Conclusion: The results from this study provide a comprehensive understanding of fungal responses to nitrogen availability.

Keywords: Proteomics, Magnaporthe oryzae, Nitrogen starvation, Melanin biosynthesis, Extracellular protein

\section{Background}

In nature, fungi, including plant pathogens, are often exposed to environments where nutrients are insufficient. To deal with such conditions, several survival mechanisms are activated such as intercellular nutrient recycling, the scavenging of resources and/ or morphological changes to aid growth and proliferation in stressful surroundings. On the plant surface, potential pathogenic fungi are often limited for nutrients until the host has been successfully infected. Indeed, the expression of pathogenicity genes are frequently elevated during nitrogen limiting conditions

\footnotetext{
* Correspondence: radean2@ncsu.edu

${ }^{1}$ Center for Integrated Fungal Research, Department of Entomology and Plant Pathology, North Carolina State University, Raleigh, NC 27695, USA Full list of author information is available at the end of the article
}

suggesting that nitrogen starvation is a driving force for successful fungal infection of their host organisms [1-3]. Unlike their plant hosts, fungi can utilize diverse compounds as nitrogen sources from primary preferred sources such as ammonium, glutamine and glutamate to other non-preferred secondary forms including nitrate, nitrite, other amino acids and proteins. Assimilation of nitrogen is tightly regulated by global regulators that ensure use of preferential nitrogen sources over less desirable sources [4]. AreA, Nit2 and NUT1, which encode GATA type transcription factors are well known as a key regulatory genes in Aspergillus nidulans, Neurospora crassa and Magnaporthe oryzae respectively [5-7]. A number of studies have linked nitrogen metabolism regulation with the ability to cause disease by plant pathogenic 
fungi, including Cladosporium fulvum, Colletotrichum lindemuthianum and M. oryzae [7-9].

The rice blast pathogen, $M$. oryzae, is the most significant fungal pathogen of rice crops worldwide as it routinely destroys rice production by $10-30 \%$ [10]. M. oryzae also infects other agronomically important grass species including wheat, barley and millet [11]. As typical of many filamentous ascomycete fungal pathogens, $M$. oryzae develops a specialized infection structure, the appressorium, to attach and penetrate the host plant. After successful colonization of host tissues, necrotic lesions form within a few days, from which conidia are produced rapidly spreading the disease to neighboring plants under favorable conditions [12].

Over the past few years, transcriptome and proteome studies during nitrogen starvation are beginning to reveal how nitrogen availability affects phytopathogens $[13,14]$. In transcriptome studies of $M$. oryzae, 520 genes showed increased gene expression during nitrogen starvation, the majority of which were involved in amino acid metabolism and uptake [13]. We found the important pathogenicity factor, SPM1, a putative subtilisin-like protease was significantly induced under nitrogen starvation as well as during appressorium formation and in response to exogenous cyclic AMP treatment [15]. Further study showed that SPM1 was localized in vacuoles and involved in autophagy during appressorium formation. Infectious growth of the spm1 deletion mutant in rice epidermal cells was very limited [16]. In other phytopathogenic fungi such as in Verticillum dahliae, the expression of 487 genes, which included genes involved in melanin biosynthesis, were significantly upregulated under nitrogen starvation [14]. Furthermore, analyses of upregulated genes under nitrogen stress has yielded numerous small secreted proteins, a feature typical of many fungal effectors $[17,18]$.

Proteomic analysis of liquid media from $V$. dahliae culture grown under nitrogen starvation showed enrichment of proteins for cell wall degradation, reactive oxygen species (ROS) scavenging and stress response as well as protein and carbohydrate metabolism [18]. Up to now, studies of the $M$. oryzae proteome under nitrogen starvation have been conducted through analysis of two-dimensional gels coupled with mass spectrometry analysis. An analysis of liquid culture media identified 85 putative secreted proteins upregulated under nitrogen starvation. The majority were cell wall hydrolase enzymes, protein and lipid hydrolases and proteins for ROS detoxification [17]. Another study reported 975 protein spots from complete media and 1169 spots under nitrogen limitation conditions. Forty three differentially accumulated proteins were identified, of which several were found to be involved in glycolysis, the tricarboxylic acid cycle and nitrogen metabolism [19].

In this comprehensive study, unfractionated protein samples coupled with advanced mass spectrometry technology was employed to identify and monitor more than $40 \%$ of the predicted $M$. oryzae entire proteome during nitrogen starvation, which revealed key biological information pertaining to its survival and pathogenicity.

\section{Methods}

Materials

All reagents were purchased from Sigma-Aldrich (St. Louis, MO) and all solvents were HPLC-grade from Honeywell Burdick \& Jackson (Muskegon, MI), unless otherwise stated.

\section{Fungal growth and protein extraction}

M. oryzae strain 70-15 conidia were harvested from 1 week old V8 agar plates and inoculated into complete liquid medium (10 g sucrose; $1 \mathrm{ml}$ of $1000 \mathrm{X}$ trace elements $(2.2 \mathrm{~g}$ $\mathrm{ZnSO}_{4}, 1.1 \mathrm{~g} \mathrm{H}_{3} \mathrm{BO}_{3}, 0.5 \mathrm{~g} \mathrm{MnCl}_{2}-4 \mathrm{H}_{2} \mathrm{O}, 0.5 \mathrm{~g} \mathrm{FeSO}_{4}$ $7 \mathrm{H}_{2} \mathrm{O}, \quad 0.17$ g CoCl $2,0.16$ g $\mathrm{CuSO}_{4}-5 \mathrm{H}_{2} \mathrm{O}, 0.15 \mathrm{~g}$ $\mathrm{Na}_{2} \mathrm{MoO}_{4}-2 \mathrm{H}_{2} \mathrm{O}$ and $5 \mathrm{~g}$ disodium EDTA per $\left.100 \mathrm{ml}\right) ; 6 \mathrm{~g}$ casein acid hydrolysate; $6 \mathrm{~g}$ yeast extract in $1 \mathrm{~L}$ ). The culture was grown at $28^{\circ} \mathrm{C}$ on a $200 \mathrm{rpm}$ shaker for 3 days. The mycelial mat was then collected on sterile filter paper, washed three times with sterile distilled water, and divided into six equal pieces. Biological replicates were grown by placing one piece of mycelial mat into each of the three flasks containing minimal media supplemented with nitrogen $(\mathrm{N}+)$, or three flasks containing nitrogen- limiting $(\mathrm{N}-)$ media. $\mathrm{N}+$ media contained $10 \mathrm{~g}$ sucrose, $1 \mathrm{ml}$ of 1000X trace element solution, $50 \mathrm{ml}$ nitrate salts $(60 \mathrm{~g}$ $\mathrm{NaNO}_{3}, 5.2 \mathrm{~g} \mathrm{KCl}, 5.2 \mathrm{~g} \mathrm{MgSO}_{4} \cdot 7 \mathrm{H}_{2} \mathrm{O}$, and $15.2 \mathrm{~g}$ $\mathrm{KH}_{2} \mathrm{PO}_{4}$ for $500 \mathrm{ml}$ ), $1 \mathrm{mg}$ thiamine and $5 \mu \mathrm{g}$ biotin per liter. $\mathrm{N}$ - media was the same as $\mathrm{N}+$ except lacked $\mathrm{NaNO}_{3}$. The $\mathrm{pH}$ of the media was adjusted to 6.5 with $\mathrm{NaOH}$. These cultures were grown at $28{ }^{\circ} \mathrm{C}$ in a $200 \mathrm{rpm}$ shaker. After $12 \mathrm{~h}$, the mycelial mats were collected, washed with sterile distilled water and then ground into powder with liquid nitrogen. Proteins were extracted using lysis buffer (50 mM HEPES (pH 7.5), 0.5\% Nonidet P-40, $250 \mathrm{mM}$ $\mathrm{NaCl}, 10 \%(\mathrm{v} / \mathrm{v})$ glycerol, $2 \mathrm{mM}$ EDTA $(\mathrm{pH} 8.0)$, one cOmplete $^{\text {Ts }}$ ULTRA tablet Protease Inhibitor cocktail (Roche, Germany) per $50 \mathrm{ml}$ ). Lysate was clarified by centrifugation at 16,000 g for $15 \mathrm{~min}$. Protein concentration was estimated using the Pierce ${ }^{\text {tw }}$ Coomassie Bradford assay kit (Thermo Fisher Scientific, Waltham, MA). Samples were stored at $-80 \mathrm{C}$.

\section{Sample preparation and digestion}

Filter aided sample preparation was performed as in Loziuk et al. [20] with slight modifications. For each biological replicate, a volume of lysate containing $250 \mu$ g of protein was reduced in $50 \mathrm{mM}$ Dithiothreitol (DTT) in $8 \mathrm{M}$ urea and $50 \mathrm{mM}$ tris- $\mathrm{HCl}$ (denaturing/alkylating buffer) at $56^{\circ} \mathrm{C}$ for $30 \mathrm{~min}$. Cysteine residues were alkylated in the dark with $10 \mathrm{mM}$ N-ethylmaleimide (NEM) for $30 \mathrm{~min}$ at room 
temperature. Samples were transferred to a $10 \mathrm{kDa}$ molecular weight cutoff centrifugation filter (EMD Millipore, Billerica, MA) and centrifuged at $14000 \mathrm{~g}$ for $15 \mathrm{~min}$ at $20{ }^{\circ} \mathrm{C}$ (all centrifugation steps performed with these settings). Buffer exchange with $2 \mathrm{M}$ urea, $10 \mathrm{mM}$ calcium chloride was performed three times by centrifugation. Samples were digested in the filter at $37^{\circ} \mathrm{C}$ for $12 \mathrm{~h}$ using a 1:50 modified porcine trypsin to sample ratio. Peptides were eluted by centrifugation, and quenched with $1 \%$ formic acid, 0.001\% Zwittergent 3-16 (Calbiochem, La Jolla, CA) for further analysis. The concentration of peptides was measured by the NanoDrop ${ }^{\text {тм }}$ (Thermo Scientific).

\section{LC-MS/MS}

Reverse-phase nano-LC was performed with an EASY nLC 1000 (Thermo Fisher, Waltham, MA) using a $20 \mathrm{~cm}, 75$ um I.D Picofrit column (New Objective, Woburn, MA) packed with Kinetix $2.6 \mu \mathrm{m}$ (100 ̊) stationary phase (Phenomenex, Torrance, CA). One microgram of peptides was loaded onto the column and eluted at a flow rate of $300 \mathrm{~nL} / \mathrm{min}$ with a 240 min linear gradient (5-30\%). Buffers consisted of mobile phase A $\left(98 \% \mathrm{H}_{2} \mathrm{O}, 2 \% \mathrm{ACN}\right.$, and $\left.0.2 \% \mathrm{FA}\right)$ and mobile phase $\mathrm{B}$ ( $2 \% \mathrm{H}_{2} \mathrm{O}, 98 \% \mathrm{ACN}$, and $\left.0.2 \% \mathrm{FA}\right)$. Three technical replicates were performed per sample, and data was collected on a Q-Exactive High Field mass spectrometer (Thermo Fisher Scientific, Waltham, MA). For $\mathrm{MS}^{1}$ scans, resolving power was 120,000, the AGC target was $3 \mathrm{e} 6$, an injection time of $50 \mathrm{~ms}$ was applied, and the scan range was set to $300-1600 \mathrm{~m} / \mathrm{z}$. During top-20 data dependent $\mathrm{MS}^{2}$ scans, resolution was 15,000 , the AGC was $1 \mathrm{e} 5$, an injection time of $30 \mathrm{~ms}$ was applied, the scan range was $200-2000 \mathrm{~m} / \mathrm{z}$, a $2 \mathrm{~m} / \mathrm{z}$ isolation window was used, normalized collision energy was set to 27 , the underfill ratio was $2 \%$ with an intensity threshold of $6.7 \mathrm{e} 4$, and a dynamic exclusion time of $20 \mathrm{~s}$ was applied.

\section{Database searching and data analysis}

Proteins were searched against a concatenated targetreverse database MG8 (Magnaporthe comparative Sequencing Project, Broad Institute of Harvard and MIT), and identified using the Sequest HT algorithm in Proteome Discoverer 1.4 (Thermo Scientific, San Jose, CA). Search parameters used a $5 \mathrm{ppm}$ precursor mass and $0.02 \mathrm{Da}$ fragment mass tolerance and allowed up to 2 missed cleavage sites. False discovery rate calculations were generated using Percolator at a $1 \%$ protein false discovery rate (FDR). Peptide spectral matches (PSMs) were normalized across technical and biological replicates, and treatment conditions using the total spectral counts method as previously described [21]. Differential protein expression was calculated by dividing the normalized PSMs of the nitrogen-starved state by the nitrogen treated state. Statistical significance of unique protein identification and protein fold-changes between the treatments was determined using a pairwise Student's ttest with a cutoff of $p \leq 0.05$.

Functional annotation was performed using David Algorithm (version 6.7) [22]. Biological pathways of identified proteins were predicted by searching the $M$. oryzae KEGG pathway database (release 79) [23]. Subcelluar localizations to all predicted proteins of the $M$. oryzae version 8 genome were assigned by the WoLF PSORT program [24]. The $500 \mathrm{bp}$ upstream of open reading frames were searched for HGATAR domains $(\mathrm{H}=\mathrm{A}, \mathrm{C}$ or $\mathrm{T}$ and $\mathrm{R}=\mathrm{A}$ or $\mathrm{G}$ ) using the POCO motif finding program [25] and the presence of HGATAR motifs were compared between gene of interests and background genes.

\section{Results and discussion}

Proteome identification in nitrogen supplemented and nitrogen depleted growth condition

In this study, the protein profiles of $M$. oryzae 70-15 mycelia grown under nitrate supplemented or nitrogen depleted conditions were compared. The fungus was initially cultivated in nutrient rich complete media for 3 days and then switched to minimal media with or without nitrogen sources for an additional $12 \mathrm{~h}$. To generate a detailed interrogation of protein changes associated with nitrogen starvation, highly sensitive, global MS/MS technologies for protein detection coupled to advanced annotation tools were employed. A total of eighteen injections from samples consisting of two nitrogen treatments (nitrate supplemented $(\mathrm{N}+)$ and nitrogen depleted $(\mathrm{N}-))$, three biological replicates and three technical replicates were investigated. On average, 153,000 tandem mass spectra were collected corresponding to an average of $23,648 \mathrm{MS}^{1}$ peptides per injection. Overall, the whole proteomic dataset mapped to a total of $5498 \mathrm{M}$. oryzae proteins (representing $>42 \%$ of the 12,991 predicted proteins in $M$. oryzae V8 annotation proteome) with a $1 \%$ FDR (Fig. 1, Additional file 1: Table S1). There were 4098 proteins shared between the two treatments, 704 found only in N-, and 696 only in $\mathrm{N}$ +. In previous work, employing FASP and anion StageTip fractionation analyzed on an Orbitrap XL, 3200 proteins were identified in M. oryzae [26]. The method used in this study did not include fractionation, which resulted in more complex samples. Nevertheless, the employ of newer MS technologies with significant higher $\mathrm{MS} / \mathrm{MS}$ scan rates resulted in an increase in proteome coverage by more than $75 \%$. Similar results have been recently reported in yeast where it is now possible to identity nearly 4000 proteins representing $\sim 60 \%$ of the theoretical proteome without sample fractionation [27]. This important advancement enabling the use of non- 


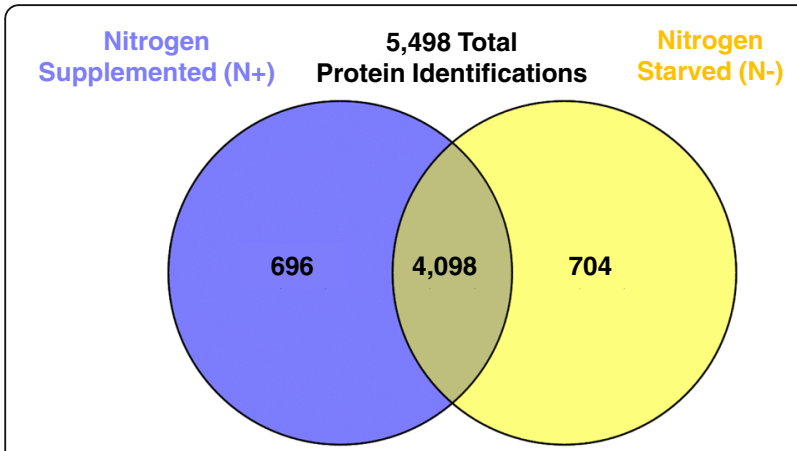

Fig. 1 Number of proteins identified from M. oryzae in this study. Venn diagram shows the number of proteins identified in either $\mathrm{N}+$ and $\mathrm{N}$ - only and those shared between both conditions

fractionated samples now paves the way for more sophisticated and complex proteome studies in the future.

The cellular localization of $M$. oryzae proteins was analyzed using the prediction tool, WoLF PSORT [24]. The WoLF PSORT distribution of the theoretical $M$. oryzae database $(12,991$ proteins) localized $15 \%, 28 \%$, $25 \%$, and $16 \%$ of the proteins to cytosol, nucleus, mitochondria, and extracellular regions, respectively (Fig. 2a). By comparison, among the 4794 identified proteins in the $\mathrm{N}+$ condition, $23 \%$ were cytosolic, $28 \%$ nuclear, $25 \%$ mitochondrial and $8 \%$ extracellular (Fig. 2b). Among the 4802 identified proteins in the $\mathrm{N}$ - condition, $23 \%$ were cytosolic, 28\% nuclear, 23\% mitochondrial and 10\% extracellular (Fig. 2d). The $\mathrm{N}+$ and $\mathrm{N}$ - proteome both showed a clear enrichment of cytosolic proteins and reduction of extracellular proteins.

Protein detection is likely to be directly related to the amount of protein present in the tissue and thus may reflect the general level of protein expression in the $\mathrm{N}+$ and $\mathrm{N}$ - conditions (high for cytosolic proteins and low for extracellular proteins). To test this hypothesis, the expression level according to cellular localization was evaluated. The relative cellular protein expression was measured by calculating the normalized spectral abundance factor (NSAF) and summed for each subcellular localization category $[28,29]$.

This analysis showed that in both nitrogen supplemented and starved conditions, the cytoplasmic and mitochondrial proteins represented not only the largest groups of identified proteins but also embodied proteins of high abundance. In contrast, extracellular proteins were underrepresented among the identified proteins and generally contained proteins of lower abundance. However, we cannot exclude the possibility that some extracellular protein were lost during sample preparation. Although, we identified the nuclear and plasma membrane proteins in the same proportion as the whole proteome, these proteins showed relatively lower protein abundance (Fig. 2c, e). These results

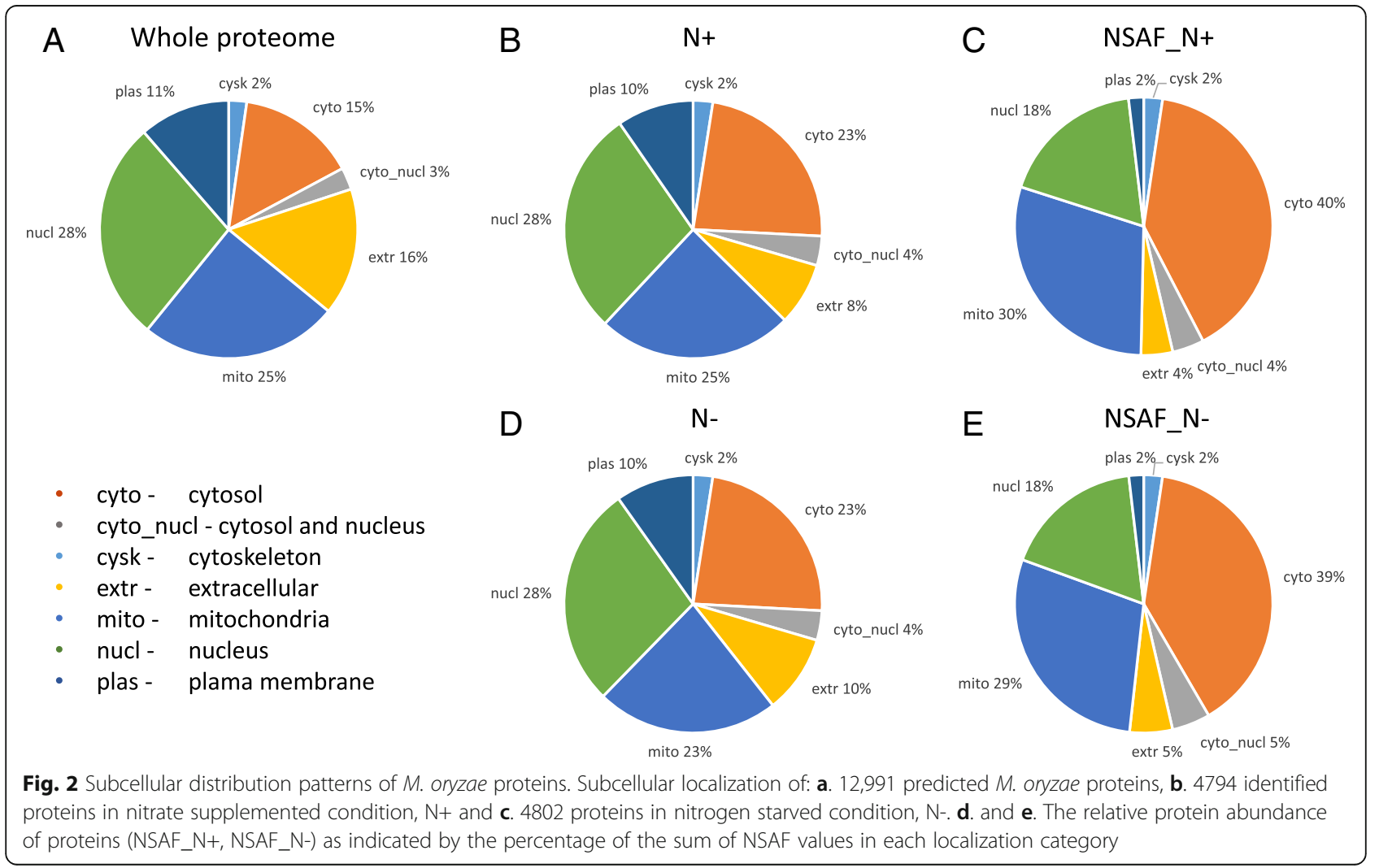


were very similar to our previous analysis of $M$. oryzae conidial proteome [30] and suggests the general enrichment of cytosolic and mitochondrial proteins in quantity and quality and underrepresentation of extracellular proteins in $M$. oryzae tissues.

Follow-up studies were performed on the highest $(\geq 90$ percentile in NSAF value) and lowest abundant $(\leq 10$ percentile NSAF value) proteins. Among the most abundant proteins in the $\mathrm{N}+$ group, the majority were cytosolic (43\%) followed by mitochondrial (30\%) proteins and 15\% nuclear proteins (Fig. 3a). A similar distribution was observed for highly abundant proteins in the $\mathrm{N}$ - condition (Fig. 3b). The highly abundant cytosolic proteins in both $\mathrm{N}$ + and $\mathrm{N}$ - were annotated as subunits of ribosome and proteasome or involved in glycolysis, amino acid biosynthesis, aminoacyl-tRNA biosynthesis, starch and sucrose metabolism or fatty acid biosynthesis. Based on KEGG pathway analysis, among the highly expressed mitochondrial proteins, 12 proteins, including NADH dehydrogenases, F-type ATPases, cytochrome $\mathrm{c}$ oxidase and cytochrome c reductase, were implicated in the processes related to oxidative phosphorylation. TCA cycle and amino acid biosynthesis related proteins and components of the ribosome were also identified in the mitochondria proteins (Additional file 1: Table S1). The most abundant extracellular proteins included cell wall modifying enzymes, such as cell wall glucanosyltransferase (MGG_00592), glucan 1,3-beta-glucosidase (MGG_04689) and beta-glucosidase 1 (MGG_09272) and different types of proteases, such as dipeptidyl-peptidase V (MGG_07877), subtilisin-like proteinase Spm1 (MGG_03670) and carboxypeptidase Y (MGG_05663). In sum, proteins associated with growth and metabolism were the most abundant.

Among the lowest abundant proteins, nuclear, plasma membrane and extracellular proteins were over-represented, whereas cytosolic and mitochondrial proteins were under-represented in both the $\mathrm{N}+$ and N- (Fig. 3c, d).

\section{Proteome changes during nitrogen starvation}

Relative quantification of protein abundance between the $\mathrm{N}+$ and $\mathrm{N}$ - conditions was determined using PSMs. One hundred fifteen and 70 proteins were found to be significantly unique (Student's T test, $p \leq 0.05$ ) in the $\mathrm{N}$ - and $\mathrm{N}$ + groups, respectively. Among the 4098 overlapping proteins, 444 proteins were identified as significantly regulated, with a 2-fold or greater change between the groups ( $p$-value <0.05). 248 proteins were over-expressed and 196 proteins were repressed in the $\mathrm{N}$ - group compared with $\mathrm{N}$ + (Fig. 4). Combining the uniquely identified with the
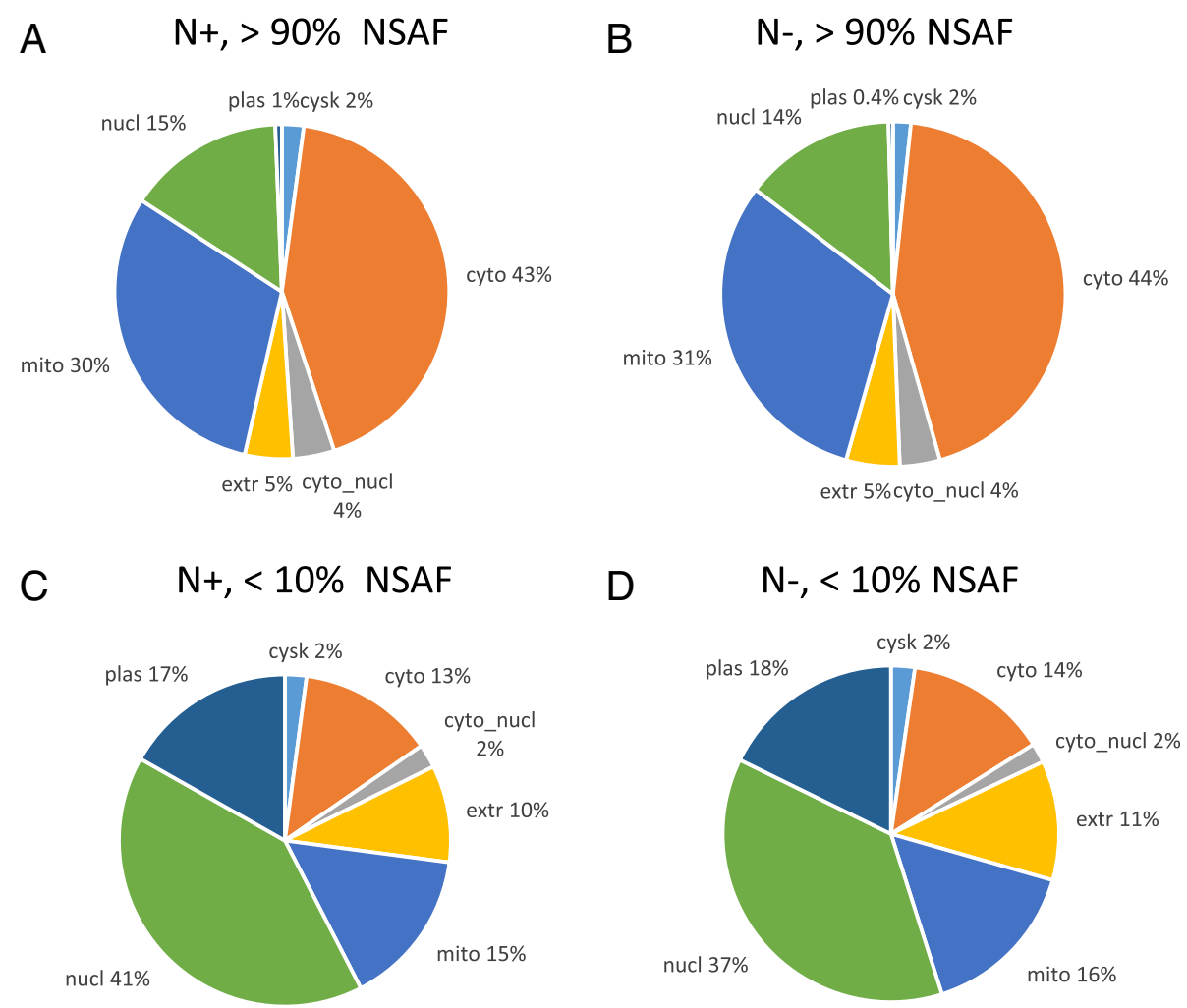

Fig. 3 Distribution of cellular localization of the most and the least abundant proteins identified in $\mathrm{M}$. oryzae under nitrate nitrogen ( $\mathrm{N}+$ ) and nitrogen starved ( $\mathrm{N}-)$ conditions. Proteins ranking in the top $90 \%(>90 \%$, a and $\mathbf{b})$ and bottom $10 \%(<10 \%$, c and $\mathbf{d})$ in NSAF value were grouped respectively according to the expected cellular location. Localization categories are shown in Fig. 2 
differentially expressed proteins resulted in 363 induced and 266 repressed proteins in fungal mycelia undergoing nitrogen starvation (Additional file 2: Table S2), which represented $11 \%$ of the total proteins identified. To investigate the potential biological implications of these 629 differentially expressed proteins, David GO Functional analysis v6.7 [22] were applied (Table 1). Groups of proteins for melanin biosynthesis, amino acid transport, cell morphogenesis, carboxylic acid transport, ion transport and tyrosine metabolic process were enriched during nitrogen starvation. By contrast, proteins for protein synthesis, nitrate assimilation, carbohydrate biosynthetic process port and porphyrin biosynthesis (Table 1) were repressed. Indepth discussion of these proteins is provided below to gain further insight into the relationship between nitrogen starvation and fungal development, signaling and effector protein expression.

\section{Redirection of nitrogen metabolism pathway}

Fungi have evolved mechanisms to uptake and convert inorganic nitrogen compounds from the environment to organic nitrogen compounds, which are incorporated into cellular substances including amino acids [31]. By so-called nitrogen assimilation, extracellular nitrate is transported into the cell by nitrate transporters and reduced to nitrite by nitrate reductase. This is further reduced to ammonia by nitrite reductase [31]. Our data suggests that in $M$. oryzae, this nitrogen assimilation process is highly regulated by controlling the production of the key enzymes. During nitrogen starvation, the production of nitrate reductase (MGG_06062) and nitrite reductase (MGG_00634) were significantly reduced, both by more than 100 fold. Further, levels of the nitrate transporter (MGG_13793) were significantly reduced in $\mathrm{N}$ - by more than 20 fold. Thus when nitrate nitrogen is limiting in the environment, fungal resources are likely directed elsewhere and enzymes required for nitrogen assimilation are greatly reduced.

Elevated levels of nitrogen regulators such as NUT1 (MGG_02755) were also observed under nitrogen starvation. NUT1 is a member of GATA family transcription factors, which includes AreA from $A$. nidulans and Nit2 from $N$. crassa, which are well known global nitrogen regulators in nitrogen catabolite repression $(\mathrm{NCR})[5,32]$. Typically, these transcription factors activate expression of nitrogen metabolic genes under nitrogen starvation. They contain Cys2/Cys2 type zinc fingers which recognize the consensus DNA sequences HGATAR in promoter sequences of target genes. Interestingly, although NUT1 is highly upreguated by nitrogen starvation in our studies, proteins involved in assimilation of nitrate, which are typically regulated by NUT1, were not up-regulated as noted above. There are possible explanations for this apparent contradictory observation. In Aspergillus nidulans, for example, the activity of AreA is subject to corepression by NmrA [33]. M. oryzae contains 3 homologs of NmrA, two of which Nmr1 and Nmr3 interact with NUT1 [34]. Also, other proteins such as the highly conserved AreB, have been shown to act as regulators of nitrogen metabolic genes [35]. Thus, it is possible that when nitrogen is lacking co-repressors or other

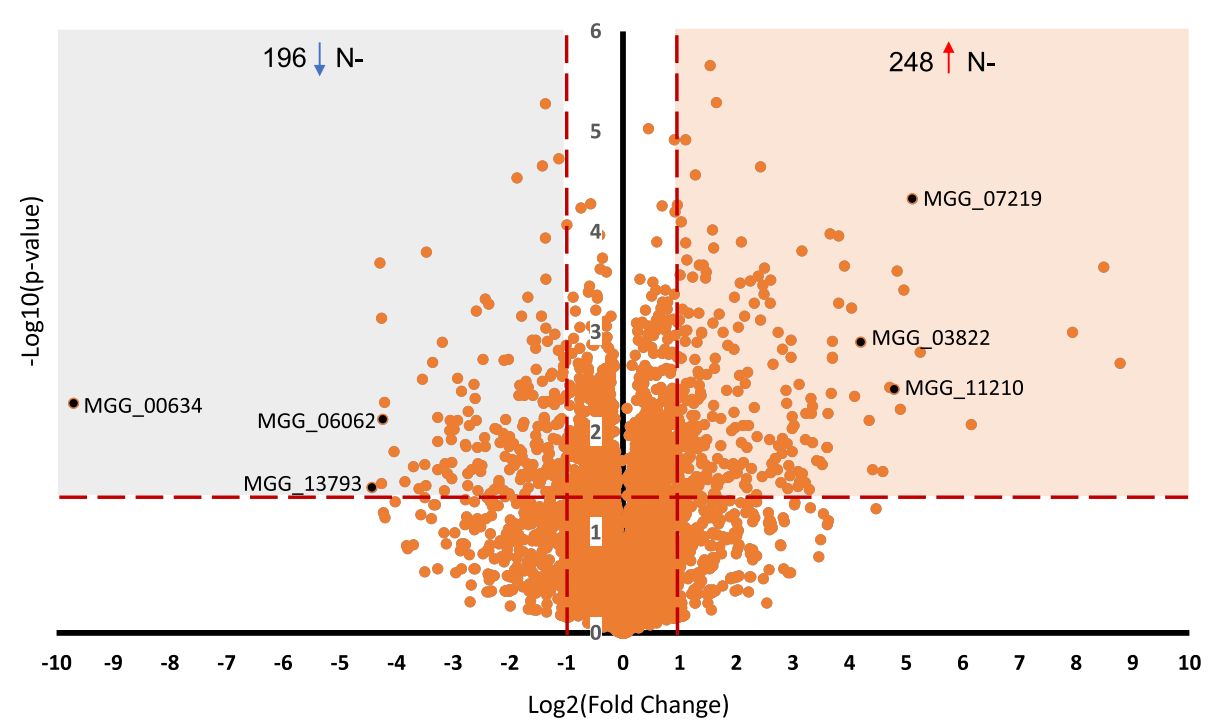

Fig. 4 Volcano plot of M. oryzae proteins from nitrate nitrogen $(\mathrm{N}+)$ and nitrogen starved $(\mathrm{N}-)$ conditions. Out of 5498 proteins identified, 444 were differentially expressed. Two hundred and forty eight were induced and 196 repressed ( $\geq 2$ fold-change, $p$-value $\leq 0.05$ ). MGG_00634 (nitrite reductase), MGG_06062 (nitrate reductase), MGG_13793 (nitrate transporter), MGG_07219 (melanin biosynthesis polyketide synthase), MGG_03822 (peptidase family T4) and MGG_11210 (beta-glucosidase 1) are highlighted 
Table 1 Enriched functional groups among differentially expressed proteins during nitrogen starvation

\begin{tabular}{|c|c|c|c|c|c|}
\hline Expression & GO ID & GO Description & Protein ID & pValue & $\begin{array}{l}\text { Enrichment } \\
\text { Score }\end{array}$ \\
\hline $\mathrm{ID}$ & GO:0042438 & $\begin{array}{l}\text { melanin biosynthetic } \\
\text { process }\end{array}$ & MGG_07216, MGG_07219, MGG_02252, MGG_05059 & 0.00 & 23.8 \\
\hline ID & GO:0046942 & $\begin{array}{l}\text { carboxylic acid } \\
\text { transport }\end{array}$ & $\begin{array}{l}\text { MGG_05128, MGG_00289, MGG_14115, MGG_01054, } \\
\text { MGG_07606, MGG_11327 }\end{array}$ & 0.02 & 4.0 \\
\hline ID & GO:0000902 & cell morphogenesis & MGG_04703, MGG_06033, MGG_03703, MGG_02781 & 0.00 & 13.2 \\
\hline ID & GO:0006570 & $\begin{array}{l}\text { tyrosine metabolic } \\
\text { process }\end{array}$ & MGG_02252, MGG_06691, MGG_05059 & 0.02 & 12.7 \\
\hline ID & GO:0006811 & ion transport & $\begin{array}{l}\text { MGG_04159, MGG_03299, MGG_10027, MGG_06118, } \\
\text { MGG_01054, MGG_02124, MGG_09119, MGG_04135, } \\
\text { MGG_10634, MGG_05281, MGG_09063 }\end{array}$ & 0.04 & 2.0 \\
\hline ID & GO:0006865 & amino acid transport & $\begin{array}{l}\text { MGG_05128, MGG_00289, MGG_14115, MGG_07606, } \\
\text { MGG_11327 }\end{array}$ & 0.05 & 3.5 \\
\hline $\mathrm{RP}$ & GO:0006412 & translation & $\begin{array}{l}\text { MGG_13783, MGG_01165, MGG_00161, MGG_07154, } \\
\text { MGG_06935, MGG_08323, MGG_04042, MGG_02511, } \\
\text { MGG_05031, MGG_04455, MGG_10825, MGG_06468, } \\
\text { MGG_05275, MGG_09301, MGG_06744, MGG_14349, } \\
\text { MGG_05647 }\end{array}$ & 0.00 & 2.3 \\
\hline $\mathrm{RP}$ & GO:0042128 & nitrate assimilation & MGG_00634, MGG_06062, MGG_04144 & 0.01 & 18.0 \\
\hline $\mathrm{RP}$ & GO:0042401 & $\begin{array}{l}\text { biogenic amine } \\
\text { biosynthetic process }\end{array}$ & MGG_10533, MGG_11574, MGG_07454 & 0.02 & 12.0 \\
\hline $\mathrm{RP}$ & GO:0008610 & lipid biosynthetic process & $\begin{array}{l}\text { MGG_06288, MGG_03343, MGG_08474, MGG_13185, } \\
\text { MGG_09239, MGG_06935, MGG_06133, MGG_07543, } \\
\text { MGG_00806 }\end{array}$ & 0.03 & 2.5 \\
\hline $\mathrm{RP}$ & GO:0006418 & $\begin{array}{l}\text { tRNA aminoacylation } \\
\text { for protein translation }\end{array}$ & $\begin{array}{l}\text { MGG_13783, MGG_00161, MGG_01165, MGG_05275, } \\
\text { MGG_04042 }\end{array}$ & 0.04 & 3.9 \\
\hline $\mathrm{RP}$ & GO:0034637 & $\begin{array}{l}\text { cellular carbohydrate } \\
\text { biosynthetic process }\end{array}$ & MGG_00865, MGG_13185, MGG_06935, MGG_00450 & 0.04 & 5.1 \\
\hline $\mathrm{RP}$ & GO:0006779 & porphyrin biosynthetic process & MGG_04860, MGG_06446, MGG_10321 & 0.05 & 8.3 \\
\hline
\end{tabular}

*Functional annotation clustering analysis was performed with 629 differentially expressed proteins using David GO v 6.7. Groups with enrichment score $\geq 2$ and $\mathrm{p}$-value $\leq 0.05$ are presented for the induced (ID) and repressed (RP) proteins during nitrogen starvation

proteins regulate the action of NUT1. In addition, other unknown factors may affect the translation or stability of nitrate assimilation proteins.

NUT1 plays a role in virulence of $M$. oryzae. Nut1 null mutants cause reduced lesion numbers compared to the wild-type [7]. NUT1 is also required for the growth on several non-preferred secondary nitrogen sources and regulates gene expression of the hydrophobin like effector, MPG1 under nitrogen starvation [7, 36]. GATA transcription factors from other plant pathogenic fungi have been shown to be key for pathogenesis. For example, CLNR1 mutants of Colletotrichum lindemuthianum are nonpathogenic [8]. Like in $M$. oryzae, these mutants can produce appressoria, but invassive growth is hampered. Reduced virulence was also reported in the FNR1 disrupted mutant in Fusarium oxysporum f. sp. lycopersici [37].

Plants contain a number of nitrogen sources that may be used by pathogenic fungi. For example, $\gamma$-aminobutyric acid (GABA) is a major metabolite in apoplast of tomato and other plants. During infection, GABA levels have been shown to rise [38, 39]. Fungi uptake GABA via GABA permease. In $A$. nidulans, expression of GABA permease, GabA is under NCR and regulated by the GATA transcription factor AreA. Here, we observed protein expression of a GABA permease MGG_14115 in M. oryzae increased more than three-fold during nitrogen starvation. However, there is no direct evidence that GABA permease is regulated by NUT1. In our previous work, gene expression of both GABA permease and NUT1 were found to be increased by nitrogen starvation [13]. This strongly suggests that in $M$. oryzae, nitrogen limitation triggers both gene expression and accumulation of proteins of major players for nitrogen scavenging including uptake of available nitrogen sources, potentially including those encountered during infection.

Our data also showed co-occurrence between nitrate metabolism and sulfate metabolism during nitrogen starvation. Key enzymes for sulfate assimilation including phosphoadenosine phosphosulfate reductase (MGG_03662), sulfite reductase flavoprotein component (MGG_00929), sulfite reductase (MGG_04144), sulfate adenylyltransferase (MGG_15027) were significantly reduced during nitrogen 
starvation. It has been reported in other biological systems that sulfate assimilation is regulated by availability of nitrogen sources and nitrogen starvation represses gene expression and enzyme activity of proteins involved in sulfate assimilation [40-42]. This may be a result of general repression of pathways involved in protein synthesis preventing the accumulation of high levels of sulfur containing amino acids such as cysteine and methionine [43].

\section{Melanin biosynthetic process}

Availability of nitrogen regulates the synthesis of broad range of secondary metabolites in fungi [44]. Melanin is one of the most thoroughly studied secondary metabolites in fungi including pathogenic fungi. Most fungi produce DHN melanins using 1,8-dihydroxynaphthalene (DHN) as precursor. Highly conserved in pathogenic filamentous fungi, DHN melanin is synthesized via the polyketide pathway. Proteins involved in this process include polyketide synthase (PKS), 1,3,6,8-tetrahydroxy-naphthalene reductase (4HNR), trihydroxy-naphthalene reductase (3HNR) and scytalone dehydratase (SCD). In $M$. orzyae, melanin biosynthesis is known to be essential for infection of the host plant [45]. A highly melanized outer cell wall of the appressorium facilitates high turgor pressure that is essential for successful penetration into the host plant [46]. Genes involved in melanin synthesis including PKS (MGG_07219), 3HNR (MGG_07216), 4HNR (MGG_02252) and SCD (MGG_05059) have been functionally characterized and shown to be essential for fungal development and pathogenicity [45]. For example, gene deletion of PKS (MGG_07219) resulted in the production of non-functional appressoria, which failed to infect the host plant $[15,47]$.

In a previous study, we showed that genes involved in this pathway were highly induced during appressorium formation and were under cAMP signaling pathways in $M$. orzyae [15]. Here, we found that proteins involved in melanin biosynthesis increased in response to nitrogen starvation in $M$. oryzae. All the principal enzymes in this pathway, PKS (MGG_07219), 3HNR (MGG_07216), 4HNR (MGG_02252) and SCD (MGG_05059), were significantly induced during nitrogen starvation. In addition, we observed mycelia were more pigmented under nitrogen starvation compared to the non-starved condition, which is likely the result of increased melanin production at least in part (Additional file 3: Figure S1). PKS (MGG_07219), 4HNR (MGG_02252) and SCD (MGG_05059) genes contains the consensus DNA sequences HGATAR in their promoter region (Additional file 2: Table S2), which suggests that expression of the melanin biosynthesis genes may be controlled by a GATA transcription factor under nitrogen starvation, possibly by NUT1.

In other fungal pathosystems, increased melanin biosynthesis has been suggested to enable infection. For example, based on the transcriptomic profiling, increased melanin biosynthesis during nitrogen starvation was proposed to be important for pathogenesis by the wilt pathogen, $V$. dahliae [14]. Increased melanin may also confer other beneficial properties. Increased melanin biosynthesis may provide protection of fungal cells from ROS during infection. For example in Colletotrichum acutatum, ROS accumulation has been reported during nitrogen limiting conditions [48]. With a strong affinity for metals, melanin acts as very effective scavenger of those free radicals. DHN melanin also protects fungal cells against permanganate, hypochlorite and neutrophil oxidative burst $[49,50]$. Melanin extracted from the medical fungus, Auricularia auricular, exhibited strong radical scavenging activities [51]. Thus, for pathogenic fungi, melanin biosynthesis is crucial for both the infection process and protection against the oxidative burst associated with host defense responses.

In other studies, expression of genes in a number of secondary metabolite gene clusters, which include polyketide synthase, have been shown to be dependent on the quantity and quality of the nitrogen source. For example, in Fusarium fujikuroi among 20 PKS gene clusters, the expression of 13 was influenced by nitrogen source [52]. In our experiments, with the exception of the PKS involved in melanin biosynthesis (MGG_07219), the expression of only one other PKS (MGG_15100) was affected by nitrogen source.

\section{Increased activity of protein degradation}

The largest group of proteins induced during nitrogen starvation was proteins involved in recycling of nitrogen sources. Exopeptidases (MGG_03822, MGG_07704, MGG_07981, MGG_09530) and metallopeptidases (MGG_01970, MGG_06643, MGG_07704, MGG_07981, MGG_09530) were induced as were 7 different endopeptidases (MGG_00922, MGG_02514, MGG_02849, MGG_02898, MGG_04031, MGG_06643, MGG_11021). It is noteworthy that certain metallopeptidases, such as AVR-PITA in $M$. oryzae, have roles associated with virulence [53]. Once proteins are degraded into amino acids, they must be translocated quickly through amino acid transporters. Five amino acid transporters (MGG_05128, MGG_00289, MGG_14115, MGG_07606 and MGG_11327) were enriched under nitrogen starvation. Increased synthesis of protein degrading enzymes and amino acid transporters suggests that during nitrogen starvation, fungi aggressively and efficiently recycle/scavenge available nitrogen sources from their own cells and/ or surrounding resources.

To identify nitrogen metabolism proteins which are potentially regulated by GATA transcription factors, HGATAR motifs within the promoters of identified proteins were searched using the POCO motif finding program [25]. The occurrence and frequency of this motif, according to the protein expression pattern, was compared in regard 
to nitrogen starvation (Additional file 4: Table S3). Among 5498 M. oryzae proteins we identified, genes encoding 3831 proteins $(69.7 \%)$ have HGATAR motifs in their promoter region. Most proteins had single (48.2\%) or double (32.2\%) motifs. A similar percentage of proteins containing the motif was found across the subset of induced and repressed proteins. However, promoters with high numbers of HGATAR motifs were enriched in induced proteins. For induced proteins, $7.6 \%$ contained 4 or more HGATAR motifs per promoter compared to $5.8 \%$ in repressed or not differentially expressed proteins. Surprising, these induced proteins with high numbers of HGATAR motifs had similar biological function; protein degradation and amino acid modification. These proteins contained an amino acid transferase (MGG_09919), an amidohydrolase (MGG_10507), an L-asparaginase 1 (MGG_04119), a dipeptidase (MGG_09530), a urease (MGG_01324) and a Lserine dehydratase (MGG_06950). These findings suggests that protein catabolism during nitrogen starvation is tightly controlled by GATA transcription factors, likely including NUT1 in M. orzyae.

\section{Increased production of putative extracellular proteins during nitrogen starvation}

Among the proteins enriched during nitrogen starvation, $27 \%$ of the proteins (99 proteins out of 363 proteins) were predicted to be extracellular proteins in contrast to only $8 \%$ of proteins ( 22 proteins out of 266 proteins) among repressed proteins. On the other hand, nuclear and mitochondrial proteins were more represented among repressed proteins (Fig. 5a). In plant pathogenic fungi, a number of small secreted proteins have been shown to act as effector proteins enabling pathogen virulence and inplanta growth $[54,55]$. Interestingly, all
22 small secreted proteins $(<250$ a.a) were identified exclusively among proteins induced by nitrogen starvation (Fig. 5b). Most of these proteins are unknown hypothetical proteins without any functional domains or orthologs in other organisms (Table 2).

Among the small proteins, the hydrophobin effector MPG1 (MGG_10315) was significantly ( $>6$ fold) induced during nitrogen starvation. MPG1 is a small hydrophobic protein involved in the surface interaction during plant infection. The gene is highly expressed in fungi during plant infection and when starved for nitrogen and carbon sources. Mpg1 mutants are non-pathogenic [2, 56]. In addition, MPG1 is regulated by NUT1 under nitrogen starvation conditions $[36,57]$. Other effector genes, such as Avr9 from Cladosporium fulvum, are highly expressed during infection and under nitrogen starvation conditions. Interestingly, the promoter of Avr9 contains mutiple GATA binding sites that are necessary for induction by the GATA transcription factor NRF1. NRF1 is also required for virulence by $C$. fulvum $[1,2]$.

We also found MGG_05344, Snodprot1, to be significantly induced by nitrogen starvation. Snodprot1 is associated with pathogenicity and was first identified to be expressed during plant infection by the wheat blotch pathogen Parastagonospora nodorum [58]. Application of the Snodprot1 protein from $M$. oryzae elicited host defense responses in rice and induced host cell death [59]. The protein was found to be essential for rice infection by M. orzyae [60].

$M$. oryzae has several lysin motif (LysM) containing proteins and one of them, MGG_07571, was expressed only in nitrogen starved condition in this study. Other LysM containing secreted proteins such as ECP6 in Cladosporium fulvum and SLP1 in M. oryzae are well characterized

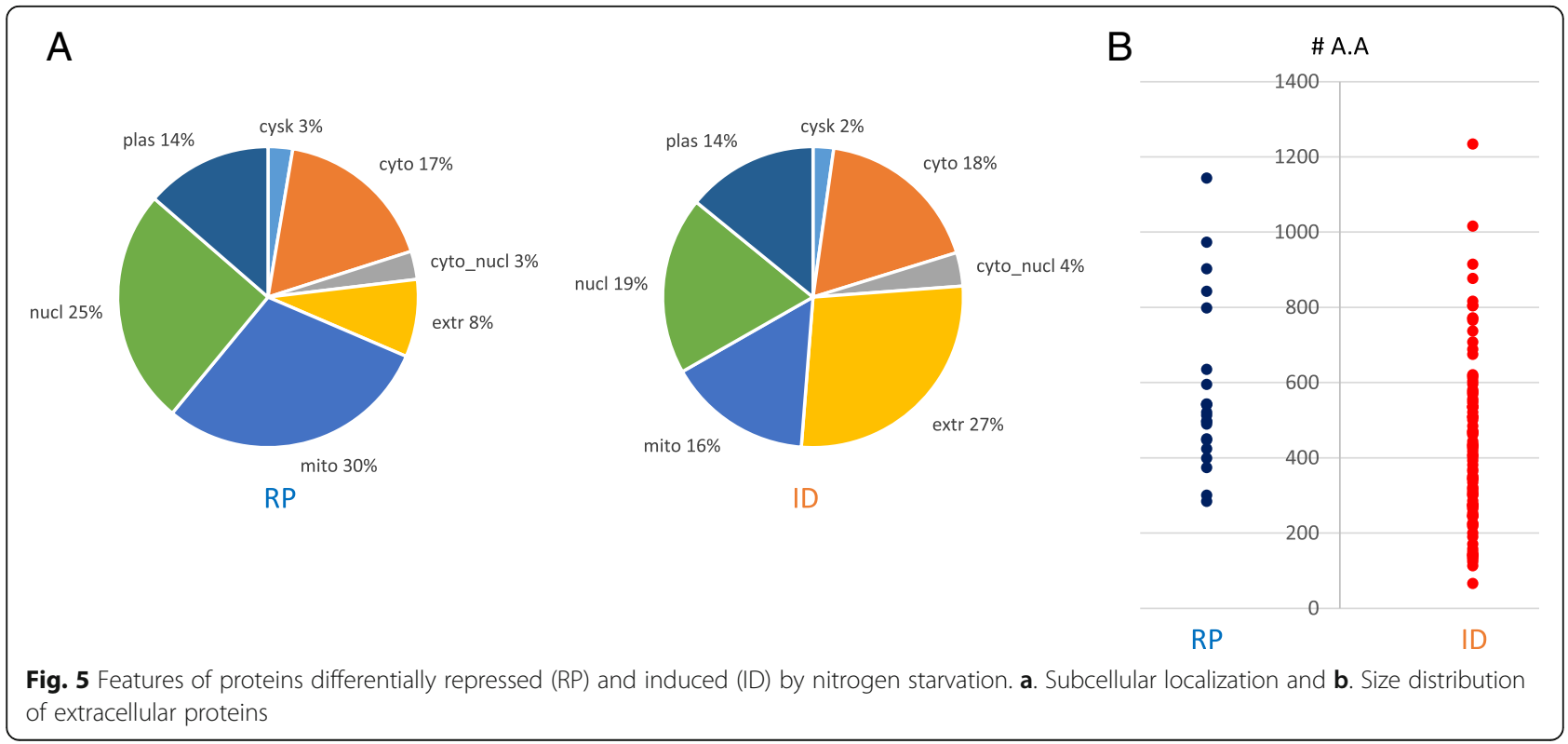


Table 2 List of small extracellular proteins enriched during nitrogen starvation

\begin{tabular}{|c|c|c|c|c|c|c|c|c|}
\hline Protein ID & Annotation & \# A.A & PSM_N+ & PSM_N- & FC & $p$ value & \# HGATAR & Cys $>3 \%$ \\
\hline MGG_09842 & hypothetical protein & 171 & 0 & 521.8 & - & 0.00 & 0 & Y \\
\hline MGG_13009 & hypothetical protein & 226 & 0 & 250.4 & - & 0.00 & 0 & \\
\hline MGG_00052 & hypothetical protein & 225 & 0 & 231.7 & - & 0.00 & 1 & \\
\hline MGG_05344 & SnodProt1 & 138 & 56 & 120.7 & 2.15 & 0.00 & 0 & \\
\hline MGG_04323 & hypothetical protein & 244 & 46.2 & 97.1 & 2.10 & 0.04 & 1 & \\
\hline MGG_07571 & $\begin{array}{l}\text { LysM domain-containing } \\
\text { protein }\end{array}$ & 143 & 0 & 64.9 & - & 0.00 & 3 & Y \\
\hline MGG_00081 & hypothetical protein & 190 & 0 & 51.3 & - & 0.01 & 1 & \\
\hline MGG_07850 & hypothetical protein & 245 & 13.4 & 50.7 & 3.78 & 0.01 & 3 & \\
\hline MGG_07782 & dehydroquinase class ॥ & 158 & 10.4 & 46.3 & 4.45 & 0.00 & 3 & \\
\hline MGG_03791 & hypothetical protein & 130 & 0 & 41.1 & - & 0.02 & 0 & Y \\
\hline MGG_13654 & hypothetical protein & 124 & 0 & 38.1 & - & 0.00 & 1 & Y \\
\hline MGG_06234 & hypothetical protein & 142 & 0 & 34 & - & 0.01 & 2 & Y \\
\hline MGG_06359 & hypothetical protein & 248 & 0 & 28.9 & - & 0.01 & 0 & \\
\hline MGG_15022 & hypothetical protein & 143 & 0 & 28.8 & - & 0.02 & 1 & \\
\hline MGG_12247 & hypothetical protein & 221 & 0 & 20.6 & - & 0.01 & 0 & \\
\hline MGG_10456 & hypothetical protein & 150 & 0 & 14.4 & - & 0.00 & 0 & Y \\
\hline MGG_10315 & $\begin{array}{l}\text { hydrophobin-like protein } \\
\text { MPG1 }\end{array}$ & 113 & 2.1 & 13.4 & 6.47 & 0.02 & 0 & Y \\
\hline MGG_03442 & hypothetical protein & 246 & 4.2 & 12.4 & 2.96 & 0.02 & 2 & \\
\hline MGG_07246 & hypothetical protein & 200 & 0 & 9.3 & - & 0.00 & 1 & Y \\
\hline MGG_07791 & surface protein 1 & 135 & 0 & 9.2 & - & 0.03 & 0 & Y \\
\hline MGG_02085 & $\begin{array}{l}\text { FAD-linked sulfhydryl } \\
\text { oxidase ALR }\end{array}$ & 218 & 0 & 8.3 & - & 0.02 & 2 & \\
\hline MGG_10604 & hypothetical protein & 66 & 0 & 5.2 & - & 0.04 & 1 & \\
\hline
\end{tabular}

${ }^{*}$ Number of spectral counts in nitrogen starved (PSM_N-) and nitrate nitrogen supplemented (PSM_N+), fold change (FC) and p-value are presented. The number of HGATAR domains in the promoter region and cysteine content of the protein are also shown

effector proteins. LysM domains bind chitin and prevent chitin triggered immune responses in the host plant [61, 62].

MGG_07791, a secreted protein homologous to a major cell surface protein CLSP1 in the bean pathogen C. lindemuthianum, was also induced by nitrogen starvation. This protein may be involved in adhesion of the pathogen to the host. However, the gene is conserved in other filamentous fungi including F. graminearum and A. nidulans [63].

Nine of the 22 small secreted proteins, including MPG1, Surface protein1 (MGG_07791), and LysM protein (MGG_07571) have more than 3\% cysteine content (Table 2). High cysteine content would likely confer structural stability to the secreted protein that in a hostile external environment such as at the host interface may enable them to work as effector proteins [64].

\section{Reduction of de novo protein production}

De novo protein synthesis is a very energy consuming process. The largest functional group (17 of 266) of repressed proteins was associated with translation. These included five tRNA synthetases (MGG_01165, isoleucyltRNA synthetase; MGG_00161, lysyl-tRNA synthetase; MGG_04042, leucyl-tRNA synthetase; MGG_05275, glutamyl-tRNA synthetase; and MGG_13783, aspartyl-tRNA synthetase) and MGG_01021, a tRNA (guanine-N(7))-methyltransferase. Protein synthesis is mediated by the ribosome complex, which is composed of dozens of proteins in both the large and small units. In our study, a number of structural constituents of the large subunit (MGG_02511, MGG_04455, MGG_05647, MGG_06468, MGG_10825) and small subunit (MGG_06744, MGG_06935) as well as mitochondrial ribosomal units (MGG_08323, MGG_09301) were repressed during nitrogen starvation. MGG_14349, a translation release factor was also down regulated.

Under nitrogen limiting conditions, active growth becomes severely challenging. Thus, an overall down-turn in the production of proteins involved in protein synthesis machinery would be not unexpected. Instead, efforts are directed to processes that can help fungi survive nitrogen limitation, including scavenging and in the case of pathogens exploiting host resources. 


\section{Conclusion}

Technological improvements in tandem mass spectroscopy and data analysis has enabled a thorough investigation of proteome changes when the rice blast fungus encounters nitrogen starvation. Representing more than $40 \%$ of the entire proteome, 5498 proteins were identified during mycelial growth with/without nitrogen sources employing total unfractionated protein samples. In depth analysis of 629 differentially enriched proteins afforded new insight into fungal responses to nitrogen starvation. Proteins associated with melanin accumulation and nitrogen scavenging were observed to increase under nitrogen stress, whereas protein synthesis and proteins associated with nitrogen assimilation decreased. This study further uncovered that nitrogen limitation triggers accumulation of secreted proteins, which may enable host plant infection or function as effector proteins. We expect further functional characterization of those differentially expressed proteins will help broaden the scope of future studies.

\section{Additional files}

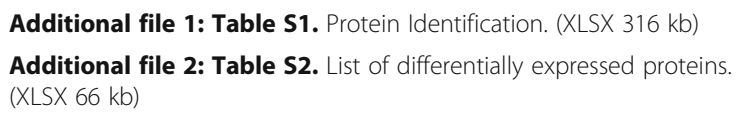

Additional file 3: Figure S1. Increased pigmentation during nitrogen starvation. (PPTX $161 \mathrm{~kb}$ )

Additional file 4: Table S3. Distribution of HGATAR motifs in M. oryzae gene promoters. (XLSX $11 \mathrm{~kb}$ )

\section{Abbreviations \\ 3HNR: trihydroxy-naphthalene reductase; 4HNR: tetrahydroxy-naphthalene reductase; A.A.: Amino acid; ACN: Acetonitrile; AGC: Automatic gain control; Cyclic AMP: Cyclic adenosine monophosphate; DHN: Dihydroxynaphthalene; DTT: Dithiothreitol; EDTA: Ethylenediaminetetraacetic acid; FA: Formic acid; FASP: Filter aided sample preparation; FDR: False discovery rate; GABA: Gamma-aminobutyric acid; HPLC: High performance liquid chromatography; KEGG: Kyoto Encyclopedia of Genes and Genomes; LC: Liquid chromatography mass spectrometry; LC-MS/MS: Liquid chromatography-tandem mass spectrometry; LysM: Lysin motif; MS: Mass spectrometry; NCR: Nitrogen catabolic repression; NEM: N-ethylmaleimide; NSAF: Normalized spectral abundance factor; PSM: Peptide spectral match; ROS: Reactive oxygen species; SCD: Scytalone dehydratase; TCA cycle: Tricarboxylic acid cycle}

\section{Acknowledgements}

Not applicable.

\section{Funding}

This material is based upon work supported by the U.S Department of Agriculture (National Institute of Food and Agriculture) under Grant Number 2014-67013-21722.

\section{Availability of data and materials}

All data generated and analyzed during this study are included in this published article (and in supplementary information files).

\section{Authors' contributions}

$Y O$ and RD designed the experiments. YO, SR and JP carried out the proteomic studies. JP and DM helped to draft the manuscript. YO and SR analyzed the data and wrote the manuscript. YO, RD and DM take full responsibility for the integrity of the data analysis. All authors read and approved the final manuscript.

Ethics approval and consent to participate

Not applicable.

\section{Consent for publication}

Not applicable.

\section{Competing interests}

The authors declare that they have no competing interests.

\section{Publisher's Note}

Springer Nature remains neutral with regard to jurisdictional claims in published maps and institutional affiliations.

\section{Author details}

${ }^{1}$ Center for Integrated Fungal Research, Department of Entomology and Plant Pathology, North Carolina State University, Raleigh, NC 27695, USA. ${ }^{2}$ W. M. Keck FT-ICR Mass Spectrometry Laboratory, Department of Chemistry, North Carolina State University, Raleigh, NC 27695, USA.

Received: 21 June 2017 Accepted: 2 November 2017

Published online: 13 November 2017

\section{References}

1. Van den Ackerveken GFJM, Dunn RM, Cozijnsen AJ, Vossen JPMJ, Van den Broek HWJ, De Wit PJGM. Nitrogen limitation induces expression of the avirulence gene avr9 in the tomato pathogen Cladosporium fulvum. MGG. Mol Gen Genet. 1994;243:277-85.

2. Talbot NJ, Ebbole DJ, Hamer JE. Identification and characterization of MPG1, a gene involved in pathogenicity from the rice blast fungus Magnaporthe grisea. Plant Cell. 1993;5:1575-90.

3. Snoeijers SS, Pérez-García A, Joosten MHAJ, De Wit PJGM. The effect of nitrogen on disease development and gene expression in bacterial and fungal plant pathogens. Eur J Plant Pathol. 2000;106:493-506.

4. Marzluf GA. Genetic regulation of nitrogen metabolism in the fungi. Microbiol Mol Biol Rev. 1997;61:17-32.

5. Caddick MX. Characterization of a major Aspergillus regulatory gene, Area. Mol. Biol. In: Filamentous Fungi. New York: V C H Publishers; 1992. p. 141-52.

6. Fu YH, Marzluf GA. Characterization of nit-2, the major nitrogen regulatory gene of Neurospora crassa. Mol Cell Biol. 1987;7:1691-6.

7. Froeliger EH, Carpenter BE. NUT1, a major nitrogen regulatory gene in Magnaporthe grisea, is dispensable for pathogenicity. Mol Gen Genet. 1996; 251:647-56.

8. Pellier A-L, Lauge R, Veneault-Fourrey C, Langin T. CLNR1, the AREA/NIT2like global nitrogen regulator of the plant fungal pathogen Colletotrichum lindemuthianum is required for the infection cycle. Mol Microbiol. 2003;48: 639-55.

9. Pérez-García A, Snoeijers SS, Joosten MHAJ, Goosen T, De Wit PJGM. Expression of the avirulence gene Avr9 of the fungal tomato pathogen Cladosporium Fulvum is regulated by the global nitrogen response factor NRF1. Mol Plant-Microbe Interact. 2001;14:316-25.

10. Greer CA, Webster RK. Occurrence, distribution, epidemiology, cultivar reaction, and management of rice blast disease in California. Plant Dis. 2001; 85:1096-102.

11. Couch BC, Kohn LM. A multilocus gene genealogy concordant with host preference indicates segregation of a new species, Magnaporthe oryzae, from M. grisea. Mycologia. 2002;94:683-93.

12. Dean RA, Talbot NJ, Ebbole DJ, Farman ML, Mitchell TK, Orbach MJ, et al. The genome sequence of the rice blast fungus Magnaporthe grisea. Nature. 2005;434:980-6.

13. Donofrio NM, Oh Y, Lundy R, Pan H, Brown DE, Jeong JS, et al. Global gene expression during nitrogen starvation in the rice blast fungus, Magnaporthe grisea. Fungal Genet Biol. 2006;43:605-17.

14. Xiong D, Wang Y, Tian C. Transcriptomic profiles of the smoke tree wilt fungus Verticillium dahliae under nutrient starvation stresses. Mol Gen Genomics. 2015;290:1963-77.

15. Oh Y, Donofrio N, Pan H, Coughlan S, Brown DE, Meng S, et al. Transcriptome analysis reveals new insight into appressorium formation and function in the rice blast fungus Magnaporthe oryzae. Genome Biol. 2008;9:R85. 
16. Saitoh H, Fujisawa S, Ito A, Mitsuoka C, Berberich T, Tosa Y, et al. SPM1 encoding a vacuole localized protease is required for infection related autophagy of the rice blast fungus Magnaporthe oryzae. FEMS Microbiol Lett. 2009;300:115.

17. Wang Y, Wu J, Park ZY, Kim SG, Rakwal R, Agrawal GK, et al. Comparative secretome investigation of Magnaporthe oryzae proteins responsive to nitrogen starvation. J Proteome Res. 2011;10:3136-48.

18. Chu J, Li W-F, Cheng W, Lu M, Zhou K-H, Zhu H-Q, et al. Comparative analyses of secreted proteins from the phytopathogenic fungus Verticillium dahliae in response to nitrogen starvation. Biochim Biophys Acta Proteins Proteomics. 2015;1854:437-48.

19. Zhou X-G, Yu P, Yao C-X, Ding Y-M, Tao N, Zhao Z-W. Proteomic analysis of mycelial proteins from Magnaporthe oryzae under nitrogen starvation. Genet Mol Res. 2016;15(2). doi:10.4238/gmr.15028637.

20. Loziuk PL, Parker J, Li W, Lin C-Y, Wang JP, Li Q, et al. Elucidation of xylem specific transcription factors and absolute quantification of enzymes regulating cellulose biosynthesis in Populus trichocarpa. J Proteome Res. 2015;14:4158-68.

21. Gokce E, Shuford CM, Franck WL, Dean RA, Muddiman DC. Evaluation of normalization methods on GeLC-MS/MSlabel-free spectral counting data to correct for variation during proteomic workflows. J Am Soc Mass Spectrom. 2011;22:2199-208

22. Huang DW, Lempicki RA, Sherman BT. Systematic and integrative analysis of large gene lists using DAVID bioinformatics resources. Nat Protoc. 2009;4:44-57.

23. Kanehisa M, Sato Y, Kawashima M, Furumichi M, Tanabe M. KEGG as a reference resource for gene and protein annotation. Nucleic Acids Res. 2016;44:D457-62.

24. Horton P, Park K-J, Obayashi T, Fujita N, Harada H, Adams-Collier CJ, et al. WoLF PSORT: protein localization predictor. Nucleic Acids Res. 2007;35: W585-7.

25. Kankainen $M$, Holm L. POCO: discovery of regulatory patterns from promoters of oppositely expressed gene sets. Nucleic Acids Res. 2005;33:427-31.

26. Franck WL, Gokce E, Oh Y, Muddiman DC, Dean RA. Temporal analysis of the Magnaporthe oryzae proteome during conidial germination and cyclic AMP (CAMP)-mediated appressorium formation. Mol Cell Proteomics. 2013; 12:2249-65.

27. Hebert AS, Richards AL, Bailey DJ, Ulbrich A, Coughlin EE, Westphall MS, et al. The one hour yeast proteome. Mol Cell Proteomics. 2014;13:339-47.

28. Paoletti AC, Parmely TJ, Tomomori-Sato C, Sato S, Zhu D, Conaway RC, et al. Quantitative proteomic analysis of distinct mammalian mediator complexes using normalized spectral abundance factors. Proc Natl Acad Sci. 2006;103: 18928-33.

29. Zybailov B, Mosley AL, Sardiu ME, Coleman MK, Florens L, Washburn MP. Statistical analysis of membrane proteome expression changes in Saccharomyces cerevisiae. J Proteome Res. 2006;5:2339-47.

30. Gokce E, Franck WL, Oh Y, Dean RA, Muddiman DC. In-depth analysis of the Magnaporthe oryzae conidial proteome. J Proteome Res. 2012;11:5827-35.

31. Crawford NM, Arst HNJ. The molecular genetics of nitrate assimilation in fungi and plants. Annu Rev. Genet. 1993;27:115-46.

32. Stewart V, Vollmer SJ. Molecular cloning of nit-2, a regulatory gene required for nitrogen metabolite repression in Neurospora crassa. Gene. 1986;46:291-5.

33. Andrianopoulos A, Kourambas S, Sharp JA, Davis MA, Hynes MJ. Characterization of the Aspergillus nidulans nmrA gene involved in nitrogen metabolite repression. J Bacteriol. 1998;180:1973-7.

34. Wilson RA, Gibson RP, Quispe CF, Littlechild JA, Talbot NJ. An NADPHdependent genetic switch regulates plant infection by the rice blast fungus. Proc Natl Acad Sci. 2010;107:21902-7.

35. Todd RB. 11 regulation of fungal nitrogen metabolism. In: Hoffmeister D, editor. Biochemistry and molecular biology. The Mycota (a comprehensive treatise on fungi as experimental systems for basic and applied research); 2016. p. 281-303.

36. Lau G, Hamer JE. Regulatory genes controlling MPG1 expression and pathogenicity in the rice blast fungus Magnaporthe grisea. Plant Cell. 1996;8:771-81.

37. Divon HH, Ziv C, Davydov O, Yarden O, Fluhr R. The global nitrogen regulator, FNR1, regulates fungal nutrition-genes and fitness during Fusarium oxysporum pathogenesis. Mol Plant Pathol. 2006;7:485-97.

38. Solomon PS, Oliver RP. The nitrogen content of the tomato leaf apoplast increases during infection by Cladosporium fulvum. Planta. 2001;213:241-9.

39. Solomon PS, Oliver RP. Evidence that gamma-aminobutyric acid is a major nitrogen source during Cladosporium fulvum infection of tomato. Planta. 2002;214:414-20.
40. Kopriva S, Suter M, von Ballmoos P, Hesse H, Krähenbühl U, Rennenberg H, et al. Interaction of sulfate assimilation with carbon andntrogen metabolism in lemna minor. Plant Physiol. 2002;130:1406-13.

41. Davidian J-C, Kopriva S. Regulation of sulfate uptake and assimilation-the same or not the same? Mol Plant. 2010;3:314-25.

42. Koprivova A, Suter M, den Camp RO, Brunold C, Kopriva S. Regulation of sulfate assimilation by nitrogen in arabidopsis. Plant Physiol. 2000;122:737-46.

43. Lee S, Kang BS. Interaction of sulfate assimilation with nitrate assimilation as a function of nutrient status and enzymatic co-regulation inbrassica juncea roots. J Plant Biol. 2005;48:270-5.

44. Tudzynski B. Nitrogen regulation of fungal secondary metabolism in fungi. Front Microbiol. 2014;5:656.

45. Chumley FG, Valent B. Genetic analysis of melanin deficient, nonpathogenic mutants of Magnaporthe grisea. Mol Plant-Microbe Interact. 1990;3:135-43.

46. Howard RJ, Valent B. Breaking and entering: host penetration by the fungal rice blast pathogen Magnaporthe grisea. Annu Rev. Microbiol. 1996;50:491-512.

47. Takano Y, Kubo Y, Kuroda I, Furusawa I. Temporal transcriptional pattern of three melanin biosynthesis genes, PKS1, SCD1, and THR1, in appressoriumdifferentiating and nondifferentiating conidia of Colletotrichum lagenarium. Appl Environ Microbiol. 1997;63:351-4.

48. Brown SH, Yarden O, Gollop N, Chen S, Zveibil A, Belausov E, et al. Differential protein expression in Colletotrichum acutatum: changes associated with reactive oxygen species and nitrogen starvation implicated in pathogenicity on strawberry. Mol Plant Pathol. 2008;9:171-90.

49. Schnitzler N, Peltroche-Llacsahuanga H, Bestier N, Zundorf J, Lutticken R, Haase G. Effect of melanin and carotenoids of Exophiala (Wangiella) dermatitidis on phagocytosis, oxidative burst, and killing by human neutrophils. Infect Immun. 1999;67:94-101.

50. Jacobson ES, Hove E, Emery HS. Antioxidant function of melanin in black fungi. Infect Immun. 1995;63:4944-5.

51. Zou Y, Zhao Y, Hu W. Chemical composition and radical scavenging activity of melanin from Auricularia auricula fruiting bodies. Food Sci Technol. 2015;35:253-8.

52. Wiemann P, Sieber CMK, von Bargen KW, Studt L, Niehaus EM, Espino JJ, et al. Deciphering the cryptic genome: genome-wide analyses of the rice pathogen Fusarium fujikuroi reveal complex regulation of secondary metabolism and novel metabolites. PLoS Pathog. 2013;9:e1003475.

53. Orbach MJ. A telomeric avirulence gene determines efficacy for the rice blast resistance gene pi-ta. Plant Cell. 2000;12:2019-32.

54. Rep M. Small proteins of plant-pathogenic fungi secreted during host colonization. FEMS Microbiol Lett. 2005;253:19-27.

55. Kim K-T, Jeon J, Choi J, Cheong K, Song H, Choi G, et al. Kingdom-wide analysis of fungal small secreted proteins (SSPs) reveals their potential role in host association. Front Plant Sci. 2016;7:186.

56. Talbot NJ, Kershaw MJ, Wakley GE, De Vries O, Wessels J, Hamer JE. MPG1 encodes a fungal hydrophobin involved in surface interactions during infection-related development of Magnaporthe grisea. Plant Cell. 1996;8: 985-99.

57. Soanes DM, Kershaw MJ, Cooley RN, Talbot NJ. Regulation of the MPG1 hydrophobin gene in the rice blast fungus Magnaporthe grisea. Mol PlantMicrobe Interact. 2002;15:1253-67.

58. Hall N, Keon JPR, Hargreaves JA. A homologue of a gene implicated in the virulence of human fungal diseases is present in a plant fungal pathogen and is expressed during infection. Physiol Mol Plant Pathol. 1999;55:69-73.

59. Wang Y, Wu J, Gon Kim S, Tsuda K, Gupta R, Park S-Y, et al. Magnaporthe oryzae-secreted protein MSP1 induces cell death and elicits defense responses in rice. Plant-Microbe Interact. 2016:29:299-312.

60. Jeong JS, Mitchell TK, Dean RA. The Magnaporthe grisea snodprot1 homolog, MSP1, is required for virulence. FEMS Microbiol Lett. 2007:273:157-65.

61. de Jonge R, van Esse HP, Kombrink A, Shinya T, Desaki Y, Bours R, et al. Conserved fungal LysM effector Ecp6 prevents chitin-triggered immunity in plants. Science. 2010;329:953-5

62. Mentlak TA, Kombrink A, Shinya T, Ryder LS, Otomo I, Saitoh H, et al. Effector-mediated suppression of chitin-triggered immunity by Magnaporthe oryzae is necessary for rice blast disease. Plant Cell. 2012;24:322-35.

63. Hoi JWS, Herbert C, Bacha N, O'Connell R, Lafitte C, Borderies G, et al. Regulation and role of a STE12-like transcription factor from the plant pathogen Colletotrichum lindemuthianum. Mol Microbiol. 2007;64:68-82.

64. Trivedi MV, Laurence JS, Siahaan TJ. The role of thiols and disulfides on protein stability. Curr Protein Pept Sci. 2009;10:614-25. 